\title{
Niobium and Chromium Rich Coatings Tailored by \\ Laser Alloying: XRD Analysis at High Temperatures
}

\author{
Adilson Rodrigues da $\operatorname{Costa}^{\mathrm{a}}$, Aldo Craievich ${ }^{\mathrm{b}}$, Rui Vilar ${ }^{\mathrm{c} *}$ \\ ${ }^{a}$ Universidade Federal de Ouro Preto, Depto. de Engenharia Metalúrgica e de Materiais \\ Campus Universitário, 35400-000 Ouro Preto - MG, Brazil \\ ${ }^{\mathrm{b}}$ Instituto de Física, Universidade de São Paulo - São Paulo, Brazil \\ 'Instituto Superior Técnico, Depto. de Engenharia de Materiais Lisboa, Portugal
}

Received: September 2, 2002; Revised: September 4, 2002

\begin{abstract}
Laser treatment technologies have been widely used to modify superficial layers of different materials. In this work we prepare $\mathrm{Nb}$ and $\mathrm{Cr}$ rich coatings according to laser alloying technique using cast iron as substrate material. $\mathrm{Nb}$ and $\mathrm{Cr}$ are intensive used in order to overcome challenges like good chemical and mechanical performance at high temperatures. Following laser alloying the surface-modified samples were submitted to an "in situ" XRD analysis under controlled high temperature and atmosphere. The phase transitions registered point to transformations that do not implies formation of fragile phases or cracks induced by high volumes modifications.
\end{abstract}

Keywords: Laser alloying, $\mathrm{Nb}$ and Chromium carbides, XRD, synchrotron radiation

\section{Introduction}

Laser treatment technologies have been widely used to modify superficial layers of different materials. In general, the aim of these treatments is to provide specific properties, such as hardness and corrosion resistance, or to develop new surfaces by means of cladding and/or alloying techniques. The laser alloying technique is based on the principle of mixing an alloying element in the melted pool of the substrate created by the laser beam at the surface. Lasersurface modification is a nonequilibrium synthesis method involving high cooling rates $\left(10^{3}-10^{8} \mathrm{k} / \mathrm{s}\right)$ which produce metastable phases by exceeding the solid-solubility limit beyond the equilibrium phase diagram; supersaturation increases due to nonequilibrium solidification ${ }^{1}$.

In this work we prepare $\mathrm{Nb}$ and $\mathrm{Cr}$ rich coatings according to laser alloying technique using cast iron as substrate material. $\mathrm{Nb}$ and $\mathrm{Cr}$ are intensive used in order to overcome challenges like good chemical and mechanical performance at high temperatures. During melting of a thin superficial layer, carbon from graphite nodules of cast-iron is available to combine with $\mathrm{Nb}$ and $\mathrm{Cr}$. This is a novel technique to obtain niobium and chromium carbides at high temperature through a solid-liquid reaction. The other methods reported in the literature are related to the use of powder mixture submitted to heating or reduction of solid reactants followed by carburization ${ }^{2}$.

Carbide rich materials are expected to have a good performance at high temperatures. This implies that the material should have a microstructure capable to resist thermal cycles, among others constraints. Carbides of refractories metals, as niobium and chromium, or particles (grains) of these metals dispersed in the matrix of a iron base material correspond to a microstructural arrangement having desired properties for high temperature uses.

Following laser alloying the surface-modified samples were submitted to an "in situ" XRD analysis under controlled high temperature and atmosphere. The proper experimental conditions were achieved using a furnace installed at XRD LNLS workstation. Basically, the experimental setup allows the determination of a series of X-ray patterns during heating and cooling processes.

The main purposes of this work were to characterise the crystalline phases and to determine microstructural changes in laser $\mathrm{Nb}$ and $\mathrm{Cr}$ alloyed coatings during heating in the range room temperature up to $750{ }^{\circ} \mathrm{C}$. The phase transi-

*e-mail: adilson@em.ufop.br, acraievi@if.usp.br, rui.vilar@ist.utl.pt Presented at the International Symposium on High Temperature Corrosion in Energy Related Systems, Angra dos Reis - RJ, September 2002. 
tions registered point to transformations that do not implies formation of fragile phases or cracks induced by high volumes modifications.

\section{Experimental Details}

The laser alloying experiments were performed using a $\mathrm{CW} 3 \mathrm{~kW} \mathrm{CO}$ laser working at $2.0 \mathrm{~kW}$. The alloying treatment was conducted by melting pre-placed commercially available $\mathrm{Nb}$ and $\mathrm{Cr}$ powders bed on the cast-iron substrates.

The diffraction experiments were conducted at the XRD synchrotron beam line of LNLS (Campinas - SP, Brazil) using a furnace placed in the center of a cylindrical camera to maintain the sample at a constant temperature during data collection. A monochromatic beam with a wavelength $\lambda=1.388 \AA$ was used and the X-ray diffraction patterns were recorded by means of an imaging plate. Information arising from this X-ray diffraction analysis may contribute to the understanding of the high temperature behaviour of the material.

Two sets of X-ray diffraction measurements were carried out. The first set corresponds to $\mathrm{Nb}$ rich samples heated up to $750{ }^{\circ} \mathrm{C}$ and maintained at this temperature during data acquisition (30 $\mathrm{min})$. In the second set the $\mathrm{Cr}$ sample was maintained at high temperatures $\left(750^{\circ} \mathrm{C}\right)$ during more than $3 \mathrm{~h}$. This annealing was performed in order to detect eventual structural modifications. The spectra were registered after different time intervals. In both cases the heating rate was $70^{\circ} \mathrm{C} / \mathrm{min}$ and the atmosphere inside the furnace was fed by a continuous $\mathrm{N}_{2}$ flux in order to avoid oxidation of the analysed material surfaces. The samples studied were discs $18 \mathrm{~mm}$ in diameter and $3 \mathrm{~mm}$ thick.

\section{Results and Discussions}

Several sequential X-ray diffraction spectra are presented in Fig. 1a and 1b). There is a modification in the microstructure as revealed by the additional Bragg peak (due to $\mathrm{Nb}_{2} \mathrm{C}$ ) appearing at high temperature. Once formed, this phase is stable and remains, unchanged during long isothermal treatments at the above mentioned temperatures ${ }^{3}$. For $\mathrm{Nb}$ coating the main phases present in the reference state (a laser alloyed coating sample at room temperature) were identified as being $\mathrm{Nb}$ and $\mathrm{NbC}$.

On the other hand, a microstructural study of niobium coating, performed by scanning electron microscopy (Fig. 2a and 2b), has revealed a coarse structure formed by very large white grains $(\mathrm{HV} \cong 700)$ immersed in a dark hard matrix $(1100 \leq \mathrm{HV} \leq 1600)$. The white grains are, in fact, large clusters of precursor niobium pure particles surrounded by a $\mathrm{Fe}-\mathrm{C}-\mathrm{Nb}$ gray matrix. These large clusters occupy around $35 \%$ of the microstructure. Their mean hardness is $700 \mathrm{HV}$. The very short time of interaction of the melted substrate with $\mathrm{Nb}$ grains does not allow a complete dissolu-

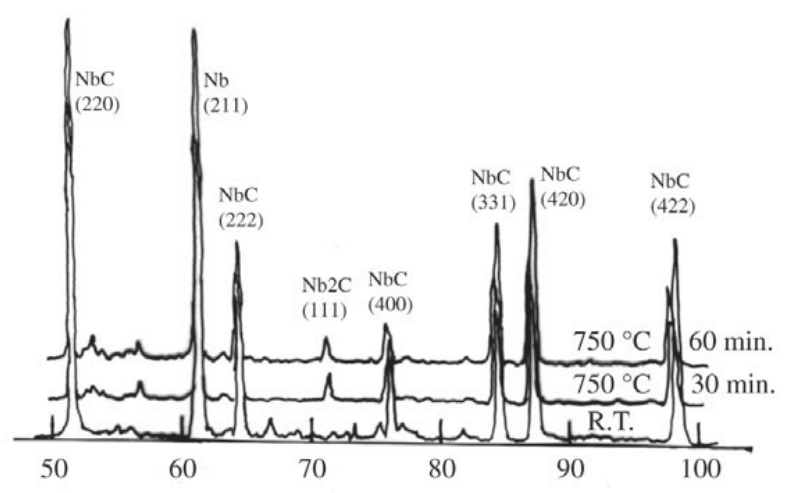

$2 \theta$

(a)

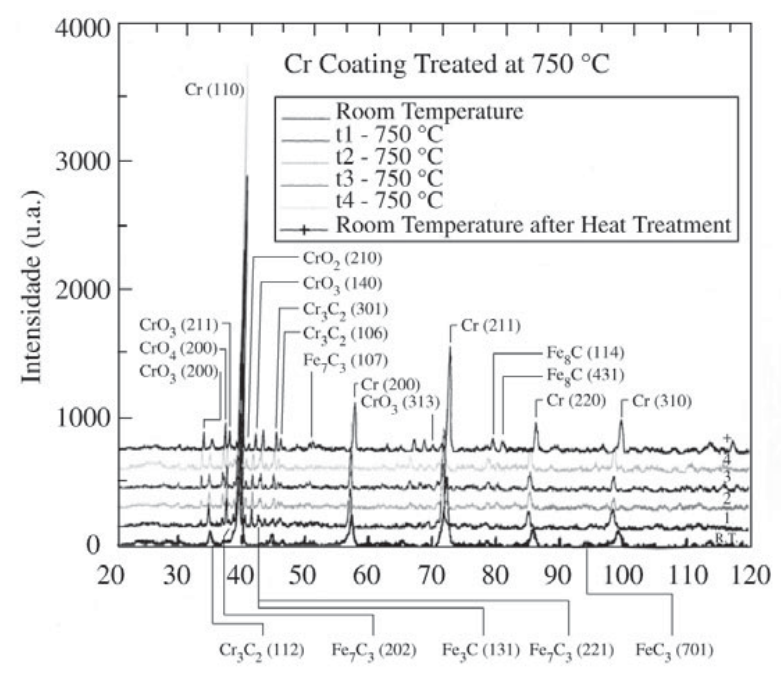

$2 \theta$

(b)

Figure 1. X-ray diffraction patterns at $750{ }^{\circ} \mathrm{C}$ : a) $\mathrm{Nb}$; b) $\mathrm{Cr}$. In both cases the pattern corresponding to the sample at room temperature (R.T.) is also plotted for comparison.

tion due to the high melting point of niobium in spite of the subsequent laser re-melting treatment. The partial dissolution of these grains into a liquid alloy rich in iron and carbon during laser melting forms a very hard matrix in which niobium carbides are the main constituents as revealed by XRD. The matrix involving the clusters, appearing as a black matrix, attain very high hardness values $-1100 \leq \mathrm{HV} \leq 1600$.

The effect of this arrangement on the wear behaviour of these surfaces was experimentally demonstrate by erosion and abrasion tests ${ }^{4}$. Microstructures like this resist very well 
when submitted to wear tests. As a consequence the overall behaviour of this niobium coating is better than that of chromium alloying as revealed by ${ }^{4}$ when dry erosion and abrasion tests were performed.

Microscopy images of the same samples after the heating cycle showed a microstructure very similar to the initial one. The close resemblance between the two microstructures (before and after cycling) is apparent in Fig. 2a and $2 b)$. Very little changes in hardness were detected confirming the overall stability of the coating.

A similar study was conducted on a $\mathrm{Cr}$ coating sample held at $750{ }^{\circ} \mathrm{C}$ (Fig. 1b). Concerning the chromium coating the diffraction study, at $750{ }^{\circ} \mathrm{C}$, shows that the previous microstructure $\left(\mathrm{Cr}, \mathrm{Cr}_{3} \mathrm{C}_{2}, \mathrm{Fe}_{3} \mathrm{C}\right)$ remains almost the same during annealing for $3 \mathrm{~h}$. The contribution of the new phases $\left(\mathrm{CrO}_{3}, \mathrm{CrO}_{2}, \mathrm{Cr}_{3} \mathrm{C}_{2}, \mathrm{Fe}_{7} \mathrm{C}_{3}\right)$ is not enough to change the overall feature of the reference spectrum showing that their volume fraction is insignificant. Despite the $\mathrm{N}_{2}$ atmosphere the formation of nitrides was not detected, maybe due to a diffusionnal barrier role played by chromium oxids appeared at the beginning o the experiments.

SEM observations confirm the almost unchanged arrangement after annealing ( see Fig. $3 a$ and $3 b$ ).

After cooling from $750{ }^{\circ} \mathrm{C}$ to room temperature $\left(70{ }^{\circ} \mathrm{C} / \mathrm{min}\right)$ the diffraction pattern remains the same registered at high temperature suggesting an irreversible micro-

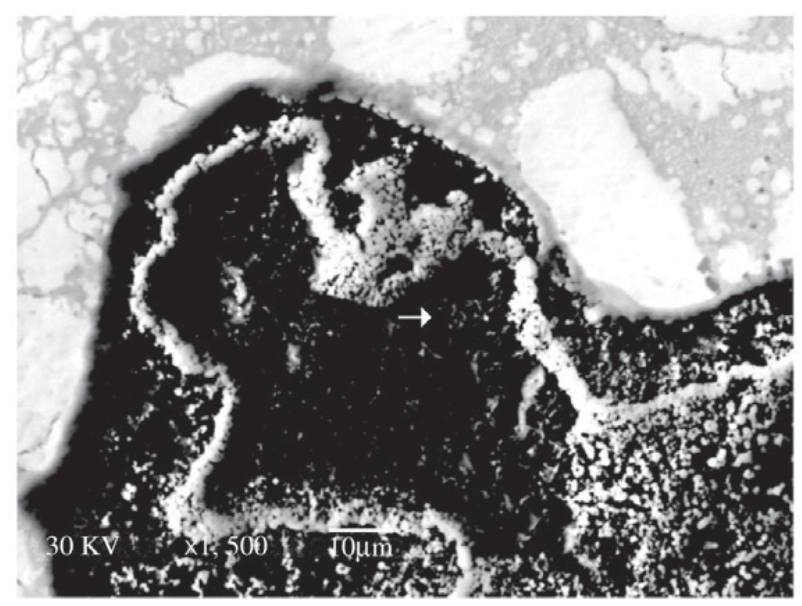

(a)

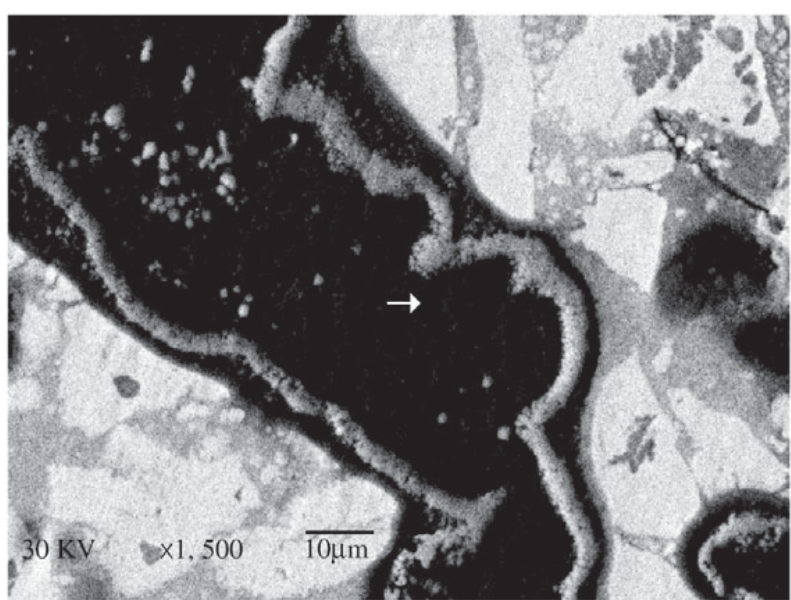

(b)

Figure 2. Scanning electron micrographies of $\mathrm{Nb}$ rich layer: a) before heating cycle; b) after heating cycle.

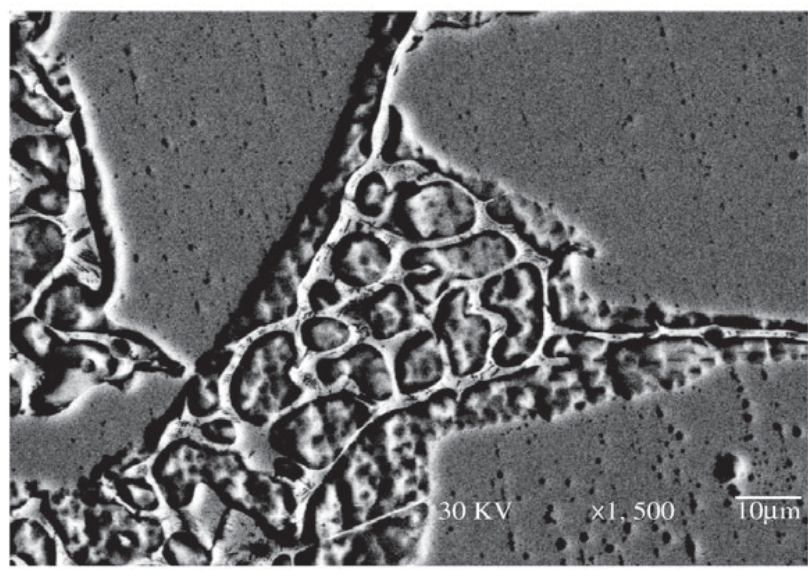

(a)

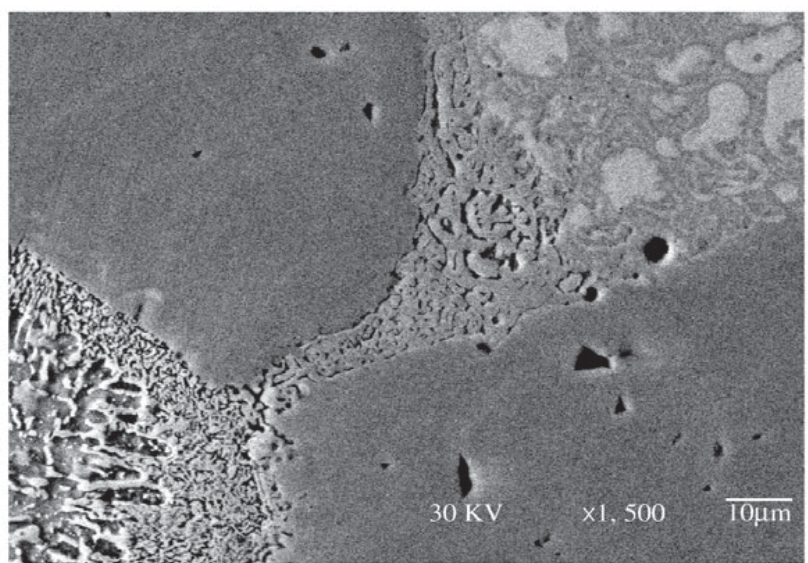

(b)

Figure 3. Scanning electron micrographies of $\mathrm{Cr}$ rich layer: a) before heating cycle; b) after heating cycle. 
structure; so, this type of cristalline pattern is adequated to high temperature applications. On the other hand, the reversibility of the diffraction peaks, during cooling, to their previous location reveals a high capacity to accomodate thermal distortions, a criterion to the selection of high performance materials.

\section{Conclusions}

Laser alloying is a technique well adapted to produce hard coatings but, when the alloying element has a very high melt point, undissolved particles may be present in the final microstructure.

Niobium carbides and chromium carbides can be obtained, in situ, by laser alloying $\mathrm{Nb}$ or $\mathrm{Cr}$ powder to a substrate having carbon in excess dispersed in the microstructure as graphite nodules in cast iron.

$\mathrm{XRD}$ results indicate the presence of a structural transformation of the $\mathrm{Nb}$ alloy heated up to $750{ }^{\circ} \mathrm{C}$. This structural change consists of a fast formation of an additional $\mathrm{Nb}_{2} \mathrm{C}$ phase.

Niobium alloys with very high content in $\mathrm{Nb}$ seem to have microstructural stability at high temperature. For chromium rich coating the microstructural stability is more evident.

For both cases the structural transformations detected by XRD corresponds to negligible microstructural change observable by scanning electron microscopy.

These experiments have shown that both alloys have a good structural response: observed phase transitions did not induce detectable damage. SEM observations did not reveal microcracks or other similar defects.

During annealing temperature the $\mathrm{Nb}$ rich microstructure develops a new arrangement that remains when sam- ples were cooled to room temperature.

In the case of chromium rich coating the phases changes concern almost only the presence of chromium oxides appeared at the latest stages of kinectic studies at $750{ }^{\circ} \mathrm{C}$. Other wise for $\mathrm{Nb}$ alloy the kinectic is different.

\section{Acknowledgement}

This work was made possible by financial support from CNPq(Brazil)/ICCTI(Portugal) under project 201283/948(NV) and by LNLS - National Synchrotron Light Laboratory, Brazil ( XRD450/99). We also acknowledge Hannes Fischer for the assistance during diffraction data processing and CBMM - Companhia Brasileira de Metalurgia e Mineração.

\section{References}

1. Vilar, R. Laser alloying and laser cladding, in Materials Science Forum Trans Tech Publications, v. 301, Switzerland, p. 229-252, 1999.

2. da Silva, A.G.P.; de Souza, C.P.; Gomes, U.U.; Medeiros, F.F.P.; Ciaravino, C.; Roubin, M. A low temperature synthesized $\mathrm{NbC}$ as grain growth inhibitor for WC-Co composites, Materials Science and Engineering A293, p. 242-246, 2000.

3. da Costa, A.R.; Craievich, A.; Vilar, R. Phase transitions in $\mathrm{Nb}$ rich coating produced by laser alloying: a synchrotron radiation diffraction study, Materials Science and Engineering A, Article in Press, 2002.

4. da Costa, A.R.; Vilar, R. Desgaste por erosão e abrasão de superfícies de um ferro fundido nodular tratado por laser, REM: R. Esc. Minas, ISSN 0370-4467, v. 53, n. 4, p. 247-251, 2000. 